\title{
KOMPARASI KINERJA ALAT PILE DRIVING ANALYZER \\ DAN SOFTWARE CAPWAP DALAM MENGHASILKAN DAYA DUKUNG ULTIMIT PONDASI TIANG
}

\author{
Oleh: \\ Rasdinanta Tarigan \\ Politeknik Negeri Medan \\ E-mail: \\ rasdinantatarigan@polmed.ac.id
}

\begin{abstract}
Buildings that stand on soft soil usually use a pile foundation. Testing the ultimate bearing capacity of pile foundations in the field is a Pile Driving Analyzer (PDA) tool. Besides being inexpensive to test, the results can also be known quickly. This tool is supported by a software called CAPWAP (CAse Pile Wave Analysis Program).In this paper, a performance comparison of the Pile Driving Analyzer (PDA) and CAPWAP (CAse Pile Wave Analysis Program) software will be presented in producing the ultimate bearing capacity of pile foundations. The results of both will be analyzed in such a way that the causes of the differences in the performance of the Pile Driving Analyzer (PDA) and the CAPWAP software are known.The results obtained show that the performance of the Pile Driving Analyzer (PDA) tool will not be optimal if the energy transferred to the pile foundation is too small. The energy given by the hammer when struck must be in the range of $1 \%-2 \%$, if it is smaller then the performance of the tool in producing the ultimate bearing capacity will not be representative. The difference in the ultimate bearing capacity between the PDA device and the CAPWAP software for energy transferred to the pile foundation (EMX) under the specified energy standard is $10.71 \%-33.23 \%$. Meanwhile, energy that meets the specified standards has a value between $0.24 \%-1.80 \%$.
\end{abstract}

Keywords: PDA, CAPWAP, Ultimate Bearing Capacity

\begin{abstract}
ABSTRAK
Bangunan yang berdiri di atas tanah lunak biasanya menggunakan pondasi tiang. Pengujian daya dukung ultimit pondasi tiang di lapangan adalah alat Pile Driving Analyzer (PDA). Pengujian ini di samping berbiaya murah, juga dapat diketahui hasilnya secara cepat. Alat ini didukung oleh suatu software yang bernama CAPWAP ( $\underline{\boldsymbol{C} \boldsymbol{A}}$ se $\underline{\boldsymbol{P}}$ ile $\underline{\boldsymbol{W}}$ ave Analysis $\underline{\boldsymbol{P}}$ rogram).

Dalam tulisan ini akan disajikan perbandingan kinerja alat Pile Driving Analyzer (PDA) dan software CAPWAP (CAse $\underline{\boldsymbol{P}}$ ile $\underline{\boldsymbol{W}}$ ave Analysis $\underline{\boldsymbol{P}}$ rogram) dalam menghasilkan daya dukung ultimit pondasi tiang. Hasil dari keduanya akan dianalisis sedemikian rupa sehingga diketahui penyebab perbedaan kinerja alat Pile Driving Analyzer (PDA) dan software CAPWAP tersebut.

Hasil penelitian yang diperoleh, diketahui bahwa kinerja alat Pile Driving Analyzer (PDA) tidak akan maksimal jika energy yang ditransfer ke pondasi tiang terlalu kecil. Energi yang diberikan hammer saat dipukulkan harus berada pada
\end{abstract}


kisaran $1 \%-2 \%$, jika lebih kecil maka kinerja alat dalam menghasilkan daya dukung ultimit tidak akan representative. Selisih daya dukung ultimit antara alat PDA dan software CAPWAP untuk energi yang ditransfer ke pondasi tiang (EMX) di baw ah standar energi yang ditentukan sebesar 10,71\% - 33,23\%. Sedangkan energi yang memnuhi standar yang ditentukan, nilainya antara $0,24 \%-1,80 \%$.

\section{Kata kunci: PDA, CAPWAP, Daya Dukung Ultimit}

\section{PENDAHULUAN}

Pondasi merupakan bagian yang sangat penting dalam dunia konstruksi. Kegagalan pondasi dapat berakibat bangunan yang berdiri di atasnya tidak berfungsi sebagaimana mestinya. Pengujian Pile Driving Analyzer (PDA) Salah satu pengujian yang sering dilakukan untuk mengetahui daya dukung ultimit pondasi tiang. Perangk at tambahan lain dari alat PDA adalah software CAPWAP. Kadangkala Daya dukung ultimit yang dihasilkan PDA dan software CAPWAP berbeda jauh. Hal ini perlu diteliti penyebab perbedaan antara PDA dan software CAPWAP. Dan mengetahui berapa besar perbedaan nilai daya dukung pondasi tiang yang dihasilkan dengan alat Pile Driving Analyzer (PDA) terhadap analisis dengan menggunakan software CAPWAP. Sehingga dalam pengujian daya dukung pondasi tiang dengan menggunakan alat Pile Driving Analyzer (PDA) ini meghasilkan nilai daya dukung yang reperesentatif. Dan yang paling penting, dapat mengetahui alat Pile Driving Analyzer (PDA) dengan baik, terutama dalam menggunakan di lapangan, maupun dalam menganalisis dengan menggunakan software CAPWAP.

\section{TINJAUAN PUSTAKA}

\section{Pengertian Pondasi Tiang}

Pondasi tiang umumnya digunakan sebagai alat meneruskan beban ke dalam lapisan tanah keras, melalui perlawanan selimut (skin friction) dan perlawanan ujung (end bearing) tiang. Ada banyak jenis pondasi tiang berdasarkan material asal, yaitu: beton- cetak di tempat (in situ) dan pra cetak (precast); baja; kayu; batu. Penampang pondasi tiang dan metode pemasangan sangat bervariasi.

Ada banyak jenis pondasi
tiang berdasarkan
pelaksanaannya, Beberapa diantaranya adalah sebagai berikut:

a. Pondasi tiang pancang (driven piles)

Pondasi tiang pancang dapat digunakan di area tanah, yang relatif lunak. Pondasi tiang pancang dicetak terlebih dahulu sebelum dimasukkan ke dalam tanah. Pondasi tiang pancang dimasukkan ke dalam tanah sampai pada lapisan tanah keras. Ada beberapa bentuk penampang dari pondasi tiang pancang, yaitu persegi, persegi panjang, melingkar, heksagonal, dll.

b. Pondasi tiang bor (bored piles)

Pondasi tiang bor biasanya dibuat dengan menggunakan tulangan yang telah dirakit, kemudian dimasukkan ke dalam lubang bor dengan kedalamanan tertentu. Selanjutnya lubang yang telah berisi tulangan diisi dengan beton.

c. Pondasi tiang sekrup (screw piles)

Pondasi tiang sekrup (screw piles) biasanya dilaksanakan dengan cara memutar pondasi sekrup tersebut ke dalam tanah 
dengan menggunakan mesin. Pondasi tiang sekrup biasanya kedalamannya tidak sedalam pondasi tiang pancang maupun pondasi tiang bor.

\section{Pile Driving Analyzer (PDA)}

Pile Driving Analyzer (PDA)

adalah suatu cara pengujian pondasi tiang dengan menggunakan data digital komputer yang diperoleh dari strain transducer dan accelerometer dan menghasilkan kurva gaya dan kecepatan ketika tiang dipukul menggunakan hammer. Hasil dari pengujian PDA terdiri dari kapasitas tiang, energi palu, penurunan, dll.

Perlengkapan pengujian Pile Driving Analyzer sebagai berikut:

a. PDA-PAX

b. Dua (2) strain transducer

c. Dua (2) accelerometer

d. Wireless koneksi

e. Peralatan tambahan, antara lain bor tangan, gerinda, dan perlengkapan safety.

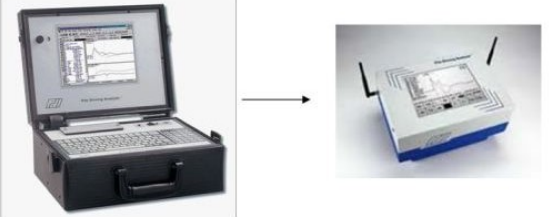

Gambar 1. Alat PDA Model PAK dan PAX

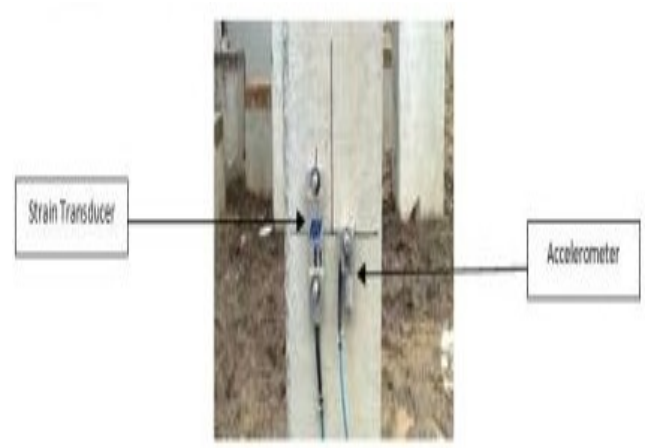

Gambar 2. Sensor PDA: Strain

Transducer \& Accelerometer

Pengujian PDA dilaksanakan

berdasrkan ASTM D4945-08.

Pekerjaan persiapan dilaksanakan sebelum pengujian dilakukan. Persiapan ini antara lain:

- Kondisi kepala tiang sebaiknya rata, simetris dan tegak lurus.

- Pasang Straintransducer harus dipasang pada garis netral dan accelerometer pada lokasi berlawanan secara diametral, dengan jarak minimal $1,5 \quad \mathrm{x}$ diameter (D) dari kepala tiang.

- Persiapkan palu dengan berat yang disyaratkan.

- Masukkan kalibrasi strain transducer dan accelerometer kemudian periksa koneksitas peralatan pengujian secara keseluruhan.

- Masukkan data tiang dan palu dalam PDA PAX.

- Setelah semua siap, periksa kembali data yang telah dimasuukkan sebelum pengujian dilaksanakan.

Setelah persiapan selesai dilaksanakan, maka pengujian dilakukan dengan menjatuhkan palu ke kepala tiang hingga diperoleh energy yang cukup dan tegangan tidak terlampaui agar kepala tiang tidak rusak. Saat pemukulan, beberapa variable akan terekam dalam komputer PDA.

Komputer PDA memberikan keluaran yang berasal dari strain tansducer dan accelerometer pondasi tiang, dan data tersebut dievaluasi sebagai berikut:

a. Data strain dikombinasikan dengan modulus elastisitas dan luas penampang tiang, memberikan tekanan vertical pada tiang. Data acceleration diintegrasi dengan waktu hasil partikel percepatan perjalanan gelombang melalui tiang, 
b. Data acceleration diintegrasi dengan waktu hasil perpindahan pondasi selama hammer dijatuhkan ke pondasi.

Menurut Robinson dkk (2002) berat hammer (W) yang dibutuhkan pada saat pengujian Pile Driving Analyzer (PDA) tergantung daya dukung ultimit pondasi tiang (Q) yaitu:

- Jenis tanah kohesif kaku atau bebatuan, maka: $\mathrm{W} / \mathrm{Q}=1 \%$

- Jenis pondasi tiang friksi pada umumnya, maka: $\mathrm{W} / \mathrm{Q}=1,5 \%$

- Jenis pondasi tiang bor dengan jenis tanah daya dukung ujung pondasi tanah berbutir kasar, maka: $\mathrm{W} / \mathrm{Q}=2 \%$

Penciptaan alat PDA ini terinspirasi dari teori yang dikembangkan oleh Jean Le Rond D'Alambert 1747, dengan persamaaan sebagai berikut:

$$
\mathrm{u}=\mathrm{F}(\mathrm{x}-\mathrm{ct})+\mathrm{G}(\mathrm{x}+\mathrm{ct}) \text {, where } \mathrm{c}^{2}=\mathrm{E} / \mathrm{p}
$$

Dikatakan bahwa ketika hammer dijatuhkan akan ada impact maka akan terjadi gelombang turun (wave down) dan gelombang naik (wave up), dengan kecepatan yang sama.

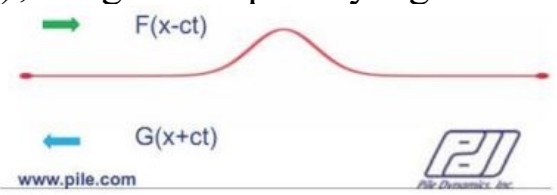

Gambar 3. Skema Gelombang Turun (Wave Down) dan Gelombang Naik (Wave Up)

Prinsip perhitungan dari alat PDA merekam sinyal force dan velocity setelah impact hammer, yaitu:

a. Force (F) diukur melalui deformasi yang terjadi (e) à $\mathrm{F}=\mathrm{E}$ A e (t) b. Velocity (V) diukur melalui percepatan yang terjadi (a) à $\mathrm{V}=$ $a(t) d t$

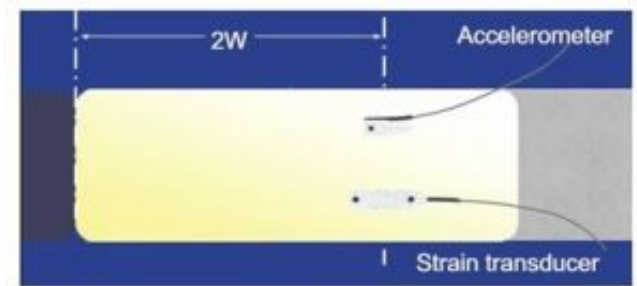

Gambar 4. Jarak Pemasangan Instrumen Dari Kepala Tiang Pancang

Berdasarkan teori "wave mechanic" pada perhitungan case method didapatkan persamaan:

$$
R=\frac{1}{2}\left(F_{t_{1}}+Z v_{t_{1}}+F_{t_{2}}-Z v_{t_{2}}\right)
$$

Dimana ;

$\mathrm{R}=$ tahanan tanah total

$\mathrm{t}_{1}=$ waktu impact dari tumbukan

$\mathrm{t}_{2}=\mathrm{t} 1+2 \mathrm{~L} / \mathrm{c}($ dimana $\mathrm{L}$ adalah panjang tiang)

$\mathrm{Z}=\mathrm{EA} / \mathrm{c}=\mathrm{A} \quad \sqrt{ }(\mathrm{Er})$ (impedance)

Tahanan total tanah $\mathrm{R}$ yang dihitung menggunakan formula di atas mempunyai dua kompenen:

a. Displacement-dependent component, Static Resistance (Rs) ini yang akan kita ukur.

b. Velocity-dependent component, Dynamic Resitance (Rd), yang mana $\mathrm{Rd}$ diturunkan dari $\mathrm{R}$ untuk mendapatkan Rs.

Variable Dynamic Resistance (Rd) sendiri dihitung dengan formula:

$$
R_{d}=J_{c} \times Z \times v_{\text {toe }}
$$

Dimana:

$\mathrm{Jc}=$ nilai damping factor, tergantung dari jenis tanah (semakin kohesif nilainya semakin besar)

$\mathrm{Z}=$ pile impedance $(\mathrm{Z}=\mathrm{EA} / \mathrm{c})$

$\mathrm{V}_{\text {toe }}=$ velocity pada ujung tiang, didapatkan dariforce and velocity yang terukur dekat 
kepala tiang.

Dengan melalui pendekatan itu didapatkan persamaan untuk menghitung nilai Static Resistance (Rs),

$$
R_{s}=\frac{\left(1-J_{c}\right)}{2}\left(F_{t_{1}}+Z v_{t_{1}}\right)+\frac{\left(1+J_{c}\right)}{2}\left(F_{t_{2}}-Z v_{t_{2}}\right.
$$

Pengujian PDA dilakukan dengan cara menumbuk ulang atau 're-impact'. Proses 're-impact' dihentikan setelah diperoleh kualitas rekaman yang cukup baik dan energi tumbukan yang relatif tinggi. Pilih salah satu data yang terbaik dari rekaman data yang telah diambil.

Setelah diperoleh data pengujian PDA, analisis lebih lanjut dilakukan dengan Program CAPWAP untuk mensimulasikan transfer beban pada tiang dan tanah, kapasitas daya dukung, friksi selimut tiang, dan penurunan tiang.

\section{Case Pile Wave Analysis Program (CAPWAP) Analyzer}

CAPWAP (CAse Pile Wave Analysis Program) adalah sebuah software yang digunakan untuk mengestimasi daya dukung total pondasi tiang serta daya dukung selimut dan daya dukung ujung pondasi tiang. Program ini menganalisis data gaya dan kecepatan yang diperoleh dari pengujian PDA di lapangan.

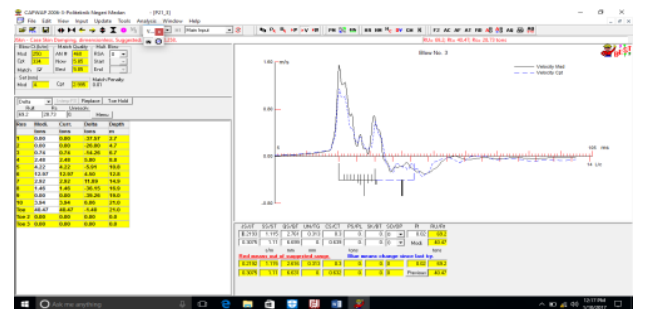

Gambar 5. Layar Analisis CAPWAP

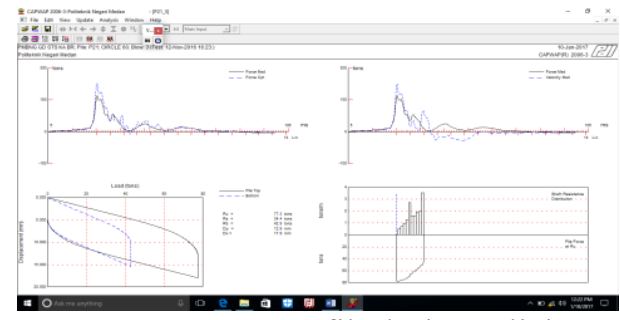

Gambar 6. Grafik dari Analisis CAPWAP

Software CAPWAP (CAse Pile Wave Analysis Program) ini merupakan satu paket dengan alat PDA. Software CAPWAP ini dilengkapi dengan sebuah dongle dalam mengoperasikannya. Software CAPWAP merupakan salah satu metode signal matching analysis (SMA). Software CAPWAP ini dapat diupdate setiap tahun dan didukung penuh produsen PDA yang ada di USA.

\section{METODE PELAKSANAAN}

Metode yang digunakan pada penelitian ini adalah pendekatan secara kuantitatif, yaitu pendekatan yang memungkinkan dilakukan pencatatan dan analisis data hasil penelitian secara eksak. Data dihimpun (teknik pengumpulan data) melalui pengujian langsung di lapangan dan kemudian dianalisis dengan suatu software.

Adapun lokasi penelitian yang dilakukan di areal Kantor Navigasi Belawan dan Areal Jembatan Sei Deli, yaitu terletak Kelurahan Belawan Bahari, Kecamatan Medan Belawan, Kota Medan. 


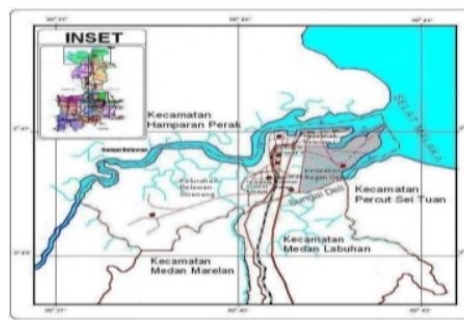

PETA KECAMATAN
MEDAN BELAWAN

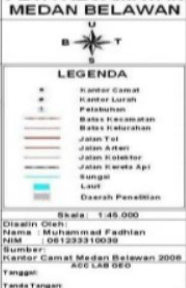

Gambar 7. Peta Lokasi Penelitian

Pelaksanaan penelitian ini terdiri dari 3 tahap, yaitu:

1. Persiapan

Sebelum pengujian lapangan dan laboratorium, maka terlebih dahulu dilakukan langkah-langkah persiapan antara lain:

a. Persiapan personil lapangan

Personil lapangan harus memahami metode pelaksanaan pengujian lapangan, baik pengujian sondir maupun pelaksanaan pengeboran tanah.

b. Persiapan alat

Alat yang digunakan dalam pelaksanaan pengujian harus dalam kondisi baik dan siap digunakan. Sebelum di lakukan pengujian lapangan, terlebih dahulu sensor strain transducer dan accelerometer di uji dengan cara memukul dengan jari tangan. Sensor dikatakan baik jika ketika dipukul dengan jari tangan maka akan muncul grafik di layar komputer PDA.

2. Pengujian lapangan Metode

pengujian lapangan dilakukan berdasarkan standard pengujian American Society for Testing Material (ASTM D4945-08).

Pengujian di laboratorium

3. Pengolahan data dan analisis

Setelah diperoleh data lapangan, maka data tersebut diolah dengan menggunakan software CAPWAP. Software CAPWAP ini merupakan satu paket dengan alat PDA yang setiap tahun dapat diupdate.

Rancangan penelitian yang akan dilaksanakan tersaji seperti diagram tulang ikan (fish bone) di bawah ini.

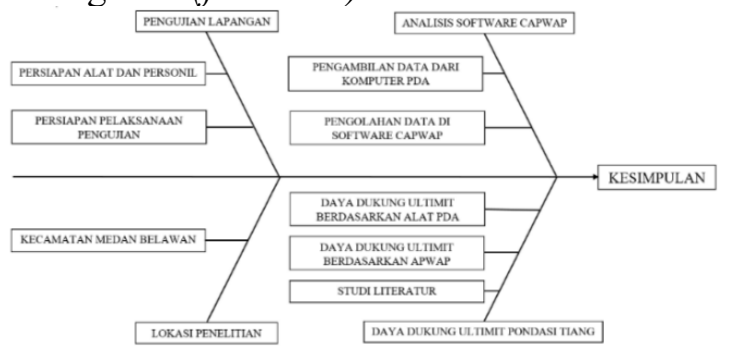

Gambar 8. Diagram Fish Bone Penelitian

\section{HASIL DAN PEMBAHASAN}

Daya dukung ultimit pondasi tiang yang diperoleh dari alat Pile Driving Analyzer (PDA) dianalisis dengan "Case Method" yang berdasarkan atas teori gelombang satu dimensi. Sementara daya dukung ultimit pondasi tiang yang diperoleh dari software CAPWAP (CAse Pile Wave Analysis Program) adalah sebuah software yang digunakan untuk mengestimasi daya dukung total pondasi tiang serta daya dukung selimut dan daya dukung ujung pondasi tiang. Analisis CAPWAP yang merupakan salah satu metode signal matching analysis (SMA).

Ada 2 (dua) lokasi yang menjadi tempat penelitian, yaitu: Jembatan Sei Deli Belawan dan Kantor Navigasi Belawan, serta disajikan satu hasil pengujian Pile Driving Analyzer (PDA) yang pernah dilakukan sebagai pembanding. Berikut ini disajikan daya dukung ultimit pondasi tiang yang diperoleh dari alat Pile Driving Analyzer (PDA) dan software CAPWAP dalam bentuk tabel dan grafik. 
Tabel 1. Hasil Penelitian Di Lokasi Jembatan Sei Deli Belawan

\begin{tabular}{|c|c|c|c|c|}
\hline $\begin{array}{l}\mathrm{N} \\
\mathrm{o}\end{array}$ & $\begin{array}{c}\text { Nama } \\
\text { Pondasi } \\
\text { Tiang }\end{array}$ & $\begin{array}{l}\text { Energi } \\
\text { Max } \\
\text { Ditransfe } \\
\text { r(EMX) }\end{array}$ & $\begin{array}{c}\text { Qult } \\
\text { Pondasi } \\
\text { Tiang } \\
\text { Hasil } \\
\text { PDA } \\
\text { (ton) }\end{array}$ & $\begin{array}{c}\text { Qult } \\
\text { Pondasi } \\
\text { Tiang } \\
\text { Hasil } \\
\text { CAPWAP } \\
\text { (ton) }\end{array}$ \\
\hline 1 & ABT1A & $1,62 \mathrm{tm}$ & 175.0 & 262.1 \\
\hline 2 & $\begin{array}{c}1 \\
\text { PIER }\end{array}$ & $2,40 \mathrm{tm}$ & 266.0 & 299.3 \\
\hline 3 & $\mathrm{C} 4$ & $1,47 \mathrm{tm}$ & 249.0 & 317.0 \\
\hline
\end{tabular}

Dari hasil pengujian lapangan dan analisis CAPWAP, tersaji seperti tabel 1 di atas. Alat pemancangan yang digunakan pada waktu pengujian adalah Diesel Kobelco K25 , dimana menurut standard alat tersebut, energi hammer yang akan dihasilkan dari alat tersebut sebesar 3,07 - 6,73 ton.meter. Tetapi pada kenyataannya energi hammer maksimum yang ditransfer ke pondasi tiang sebesar:

- ABT1A8 = 1,62 ton.meter

- ABT1A8 = 2,40 ton.meter

- PIER C4 = 1,47 ton.meter

Terlihat bahwa energi hammer yang ditransfer ke pondasi tiang lebih kecil dari standard alat pemancang Diesel Kobelco K-25. Hal ini yang menyebabkan perbedaan daya dukung ultimit yang cukup besar antara yang dihasilkan alat PDA dan software CAPWAP. Dari pengamatan di lapangan, alat pemancangan pondasi digunakan saat pemancangan berbeda dengan saat pengujian. Ada beberapa kali pengujian yang gagal dikarenakan alat Diesel Kobelco K-25 tersebut belum "panas" (belum maksimal penggunaannya).

Tabel 2. Hasil Penelitian Di Lokasi Kantor Navigasi Belawan

\begin{tabular}{|c|c|c|c|c|}
\hline No & $\begin{array}{c}\text { Nama } \\
\text { Pondasi } \\
\text { Tiang }\end{array}$ & $\begin{array}{c}\text { Energi Max } \\
\text { Ditransfer } \\
\text { (EMX) }\end{array}$ & $\begin{array}{c}\text { Qult Pondasi } \\
\text { Tiang } \\
\text { Hasil PDA } \\
\text { (ton) }\end{array}$ & $\begin{array}{c}\text { Qult Pondasi } \\
\text { Tiang } \\
\text { Hasil CAPWAP } \\
\text { (ton) }\end{array}$ \\
\hline 1 & P23 & $0,39 \mathrm{tm}$ & 55.0 & 61.6 \\
2 & P34 & $0,75 \mathrm{tm}$ & 60.0 & 61.1 \\
\hline \multicolumn{4}{|c|}{- P23 $=0,39$ ton.meter }
\end{tabular}

Dari hasil pengujian lapangan dan analisis CAPWAP, tersaji seperti tabel 2 di atas. Alat pemancangan yang digunakan pada waktu pengujian adalah Drop Hammer dengan berat $900 \mathrm{~kg}$ dengan tinggi jatuh 1 meter. Daya dukung ultimit rencana di lokasi tersebut adalah 60 ton, sehingga energi yang dibutuhkan per meter adalaah $1 \%-1,5 \%$ dari daya dukung ultimit rencana. Sehhingga energi yang dibutuhkan pada waktu pengujian sebesar $0,6-$ 0,9 ton.meter. Tetapi pada kenyataannya energi hammer maksimum yang ditransfer ke pondasi tiang sebesar:

\section{- P34 = 0,75 ton.meter}

Terlihat bahwa energi hammer yang ditransfer ke pondasi tiang P23 lebih kecil dari syarat energi yang dibutuhkan, sehingga diperoleh perbedaan yang cukup besar antara Alat PDA dan software CAPWAP. Pada pondasi tiang P34 energi hammer yang ditransfer masih sesuai dengan syarat energi yang dibutuhkan, sehingga daya dukung ultimit pondasi tiang yang diperoleh antara Alat PDA dan software CAPWAP hampir sama. 
Tabel 3. Hasil Pengujian Yang Pernah Dilakukan

\begin{tabular}{|c|c|c|c|c|}
\hline No & $\begin{array}{c}\text { Nama } \\
\text { Pondasi } \\
\text { Tiang }\end{array}$ & $\begin{array}{c}\text { Energi } \\
\text { Max } \\
\text { Ditransfer } \\
\text { (EMX) }\end{array}$ & $\begin{array}{c}\text { Qult Pondasi } \\
\text { Tiang } \\
\text { Hasil PDA } \\
\text { (ton) }\end{array}$ & $\begin{array}{c}\text { Qult Pondasi } \\
\text { Tiang } \\
\text { Hasil CAPWAP } \\
\text { (ton) }\end{array}$ \\
\hline 1 & P1.10.17 & $7.53 \mathrm{tm}$ & 446.0 & 451.9 \\
2 & P1.9.31 & $5.68 \mathrm{tm}$ & 465.0 & 466.1 \\
\hline
\end{tabular}

Dari hasil pengujian lapangan dan analisis CAPWAP, tersaji seperti tabel 2 di atas. Alat pemancangan yang digunakan pada waktu pengujian adalah Diesel Kobelco K45, dimana menurut standard alat tersebut, energi hammer yang akan dihasilkan dari alat tersebut sebesar 5,09 - 12,11 ton.meter. Tetapi pada kenyataannya energi hammer maksimum yang ditransfer ke pondasi tiang sebesar:

- P1.10.17 = 7,53 ton.meter

- P1.9.31 = 5,68 ton.meter

Terlihat bahwa energi hammer yang ditransfer ke pondasi tiang sesuai dengan standard alat pemancang Diesel Kobelco K-45. Hal ini yang menyebabkan perbedaan daya dukung ultimit yang cukup besar antara yang dihasilkan alat PDA dan software CAPWAP sangat kecil. Dari pengamatan di lapangan, alat pemancangan pondasi digunakan saat pemancangan sama dengan saat pengujian. Sehingga hasil pengujian lapangan dengan analisis software CAPWAP perbed aannya kecil.

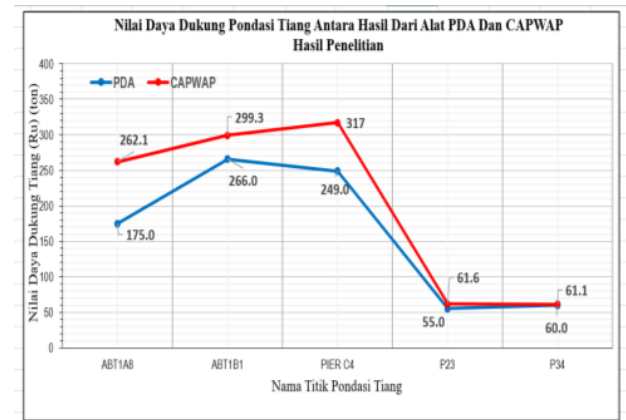

Gambar 9. Grafik Nilai Daya Dukung Tiang Dari Alat PDA Dan CAPWAP Hasil Penelitian

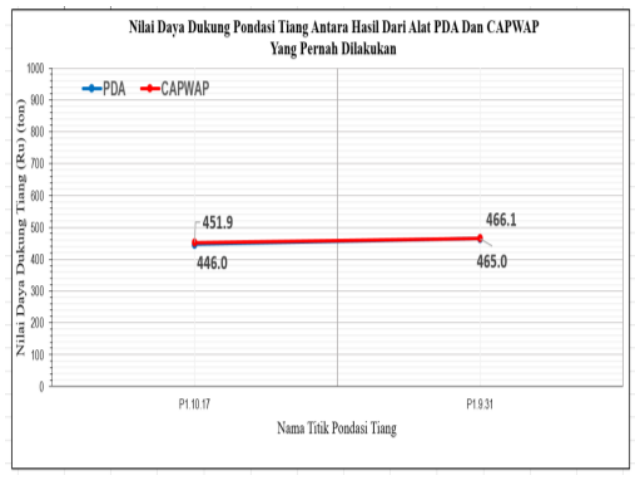

Gambar 10. Grafik Niai Daya Dukung Tiang Dari Alat PDA Dan CAPWAP Yang Pernah Dilakukan

Selisih nilai daya dukung ultimit yang dihasilkan alat Pile Driving Analyzer (PDA) dan software CAPWAP adalah sebagai berikut.

Tabel 4. Prosentase Selisih Hasil Pengujian Antara PDA Dan CAPWAP

\begin{tabular}{|c|c|c|c|c|c|}
\hline No & $\begin{array}{c}\text { Nama } \\
\text { Pondasi } \\
\text { Tiang }\end{array}$ & $\begin{array}{c}\text { Qult } \\
\text { Pondasi } \\
\text { Tiang } \\
\text { Hasil } \\
\text { PDA } \\
\text { (ton) }\end{array}$ & $\begin{array}{c}\text { Qult } \\
\text { Pondasi } \\
\text { Tiang } \\
\text { Hasil } \\
\text { CAPWAP } \\
\text { (ton) }\end{array}$ & $\begin{array}{l}\text { Selisih } \\
\text { Qult } \\
\text { Pondasi } \\
\text { Tiang } \\
\text { (ton) }\end{array}$ & $\begin{array}{l}\text { Prosentase } \\
\text { Selisih } \\
\text { Qult } \\
\text { Pondasi } \\
\text { Tiang (\%) }\end{array}$ \\
\hline 1 & $\begin{array}{l}\text { ABT 1A8 } \\
\text { ABT 1B1 } \\
\text { PIER C4 }\end{array}$ & $\begin{array}{l}175.0 \\
266.0 \\
249.0\end{array}$ & $\begin{array}{l}262.1 \\
299.3 \\
317.0 \\
\end{array}$ & $\begin{array}{l}87.1 \\
33.3 \\
68.0\end{array}$ & $\begin{array}{l}33.23 \\
11.13 \\
21.45\end{array}$ \\
\hline 2 & $\begin{array}{l}\text { P23 } \\
\text { P34 }\end{array}$ & $\begin{array}{l}55.0 \\
60.0\end{array}$ & $\begin{array}{l}61.6 \\
61.1\end{array}$ & $\begin{array}{l}6.6 \\
1.1\end{array}$ & $\begin{array}{c}10.71 \\
1.80\end{array}$ \\
\hline 3 & $\begin{array}{l}\text { P1.10.17 } \\
\text { P1.9.31 }\end{array}$ & $\begin{array}{l}446.0 \\
465.0\end{array}$ & $\begin{array}{l}451.9 \\
466.1\end{array}$ & $\begin{array}{l}5.9 \\
1.1\end{array}$ & $\begin{array}{l}1.31 \\
0.24\end{array}$ \\
\hline
\end{tabular}

Dari hasil pengujian lapangan dan analisis CAPWAP serta data pengujian yang pernah dilakukan maka terdapat perbedaan hasil yang diperoleh dari pengujian lapangan dan analisis software CAPWAP. Untuk energi yang ditransfer ke pondasi tiang (EMX) yang di bawah 
syarat yang ditentukan, maka selisih nilai daya dukung ultimit pondasi tiang antara yang dihasilkan alat Pile Driving Analyzer (PDA) dan software CAPWAP akan besar, nilainya antara $10,71 \%-33,23 \%$. Sementara jika energi yang ditransfer ke pondasi tiang (EMX) yang sesuai dengan syarat yang ditentukan, maka selisih nilai daya dukung ultimit pondasi tiang antara yang dihasilkan alat Pile Driving Analyzer (PDA) dan software CAPWAP akan kecil, Nilainya antara $0,24 \%-1,80 \%$.

\section{SIMPULAN}

Dari data dan analisis yang telah dilakukan, maka dibuat beberapa simpulan yaitu antara lain:

1. Besar energi hammer yang diberikan ke pondasi tiang saat melakukan pengujian Pile Driving Analyzer (PDA) sangat mempengaruhi hasil daya dukung ultimit pondasi tiang.

2. Pada lokasi jembatan sei Deli besar energi yang ditransfer (EMX) saat pengujian di bawah standard energi yang ditentukan, selisih daya dukung ultimit antara alat PDA dan software CAPWAP sebesar 33,3 - 87,1 ton. Pada kantor navigasi Belawan, pada titik yang EMX di bawah standard (P23) sebesar 6,6 ton sedangkan titik yang EMX memenuhi standar (P34) selisih daya dukung ultimit antara alat PDA dan software CAPWAP sebesar 1,1 ton. Sedangkan dari data pembanding yang pernah diuji, besar energi yang ditransfer (EMX) saat pengujian memenuhi standard energi yang ditentukan, selisih daya dukung ultimit antara alat PDA dan software CAPWAP sebesar 1,1 - 5,9 ton.

3. Prosentase selisih daya dukung ultimit antara alat PDA dan software CAPWAP untuk EMX di bawah standar energi yang ditentukan sebesar 10,71\% $33,23 \%$. Sedangkan energi yang ditransfer ke pondasi tiang (EMX) yang sesuai dengan syarat yang ditentukan, maka selisih nilai daya dukung ultimit pondasi tiang antara yang dihasilkan alat Pile Driving Analyzer (PDA) dan software CAPWAP akan kecil, Nilainya antara $0,24 \%-1,80 \%$.

\section{DAFTAR PUSTAKA}

Annual Book of ASTM Standards, 2008., Easton, MD, USA.

Hardiyatmo, Hary Christady, 2002. Teknik Pondasi 2. Gajah Mada University Press, Yogyakarta.

Kamalendran, A., dan Rajavaran, L.N., 2007., "Comparison of Ultimate Bearing Capacity Obtained By Pile Driving Analyzer And Maintained Load Test". Thesis, University Technology Malaysia, Malaysia.

Nakazawa, K., Sosrodarsono, S, 1983. Mekanika Tanah dan Teknik Pondasi. Pradya Paramita, Jakarta.

Pile Dynamic, Inc. 2009., "PDA-W Manual of Operation"., Cleveland, Ohio 44128, USA.

W.G. Curtin and G. Shaw, together with G.I. Parkinson, J.M. Golding and N.J. Seward, 2006. Structural Foundation Designers' Manual. Blackwell Publishing Asia Pty Ltd, 550 Swanston Street, Carlton, Victoria 3053, Australia. 